\title{
Association of Nutrition Knowledge, Practice, Supplement use and Nutrient Intake with Athletic Performance Among Taekwondo Players in Nepal
}

Dev Ram Sunuwar ( $\nabla$ devramsunuwar@gmail.com )

Nepal Armed Police Force Hospital https://orcid.org/0000-0002-2544-8296

Devendra Raj Singh

Asian College for Advance Studies, Purbanchal University

Man Prasad Bohora

Asian College for Advance Studies, Purbanchal University

Vintuna Shrestha

Tribhuvan University Institute of Medicine

Kshitij Karki

Asian College for Advance Studies, Purbanchal University

Pranil Man Singh Pradhan

Tribhuvan University Institute of Medicine

\section{Research article}

Keywords: Nutritional knowledge, Supplement use, Nutrient intake, Athletic performance, Taekwondo, Nepal

Posted Date: May 27th, 2020

DOI: https://doi.org/10.21203/rs.3.rs-29955/v1

License: (c) (1) This work is licensed under a Creative Commons Attribution 4.0 International License. Read Full License 


\section{Abstract}

Introduction: Adequate nutrition knowledge and dietary intake are important for enhancing athletic performance. Athletes are more likely to be tired and perform poorly during sports when they do not get enough diet. To the best of our knowledge, this study is first of its kind to measure the association of nutritional knowledge, practice, supplement use, and nutrient intake with athletic performance among Nepalese Taekwondo (TKD) players.

Methodology:We conducted an analytical cross-sectional study among 293 Taekwondo players of Kathmandu Metropolitan City, between August 2019 and January 2020. A two-stage cluster random sampling technique was used to select the desired number of respondents for the study. Face-to-face interviews were carried out using semi-structured questionnaires. Nutrition knowledge (NK), nutrition practice (NP), supplement use, nutrient intake using 24-hour dietary recall, and anthropometric measurements were taken. A handgrip dynamometer was used to assess the handgrip strength (HGS), as an indirect measure of athletic performance. Univariate and bivariate analyses were employed to find out the association of predictor and outcome variables. Data were analyzed using STATA/MP version 14.1 .

Results: Out of 293 participants, more than half (56.31\% and 55.63\%) had poor nutrition knowledge and nutrition practice scores respectively. Total energy intake (2368 Kcal) and protein (13.28\%), fat (15.85\%), calcium (416 mg), and iron (7 mg) respectively were significantly lower than corresponding Recommended Dietary Allowances (RDA) except carbohydrates intake (71.41\%). Nutritional knowledge $(r=0.117)$, height $(r=0.538)$, weight $(r=0.651)$, BMI $(r$ $=0.347)$, fat $(r=0.075)$, and energy (0.127) intake showed significant positive correlation with handgrip strength of athletes. The athletic performance were positively associated with training hours per day ( $\beta=0.41,95 \% \mathrm{Cl}: 0.09-0.91), \mathrm{BMI}(\beta=0.35,95 \% \mathrm{Cl}: 0.09-0.61), \mathrm{NK}$ score $(\beta=0.13,95 \% \mathrm{Cl}: 0.01-0.25)$, and energy intake $(\beta=0.13,95 \% \mathrm{Cl}: 0.12=0.14)$.

Conclusions: The results suggested that nutritional knowledge and nutrient intake both were poor among TKD athletes. Height, weight, BMI, nutritional knowledge, energy, and fat intake were positive correlation with athletic performance. Further well-constructed longitudinal research is warranted to identify the robust relationship between nutritional knowledge, practice, different supplement use, and nutrient intake among athletes.

\section{Background}

Taekwondo, also known as Tae Kwon Do (TKD), is the finest and oldest form of martial art and combat sport, originated in Korea dating back more than 2000 years [1], that has gained an international reputation, and stands among the official Olympic Games since the "Sydney 2000" Olympic Games [2, 3]. The World Taekwondo Federation (WTF) defined TKD as "the right way of using all parts of the body to stop fights and help to build a better and more peaceful world" [1]. Meanwhile, its interest has gained momentum from participants, national governments, and scientists alike, which is evolving as a martial art sport in the world [3, 4]. TKD is practiced by an estimated 80 million people in 210 countries, making it one of the world's most popular sports [1]. TKD was introduced in Nepal as a martial arts discipline in 1983. According to the Nepal Taekwondo Association total 85 schools are formally registered across the country so far [5]. TKD is a predominantly anaerobic sport (both alactacide and lactacide) with a significant aerobic component too [2]. To meet the optimum sports performance by TKD players, besides physical, technical, and tactical training, a sporting lifestyle during which adequate nourishment has a leading role $[2,6]$.

As TKD is a weight class sport, the nutritional status of the athletes is an important aspect of performance [4]. According to the joint position statement authored by the American Dietetic Association (ADA), the Dietitians of Canada and the American College of Sports Medicine (ACSM), states that optimal nutrition enhances athletic performance and recovery from exercise [7]. Optimum nutritional knowledge and adequate nutrient have been considered as the key components that play a pivotal role in enhancing athletic performance [8,9]. Inadequate nutrition knowledge can have a serious impact on the nutritional status and performance of athletes [10]. Nutrition knowledge and attitudes affect eating habits and inadequate nutritional knowledge may contribute to poor dietary behaviors resulting in diminished athletic performance [11]. Incomplete and inadequate information provided by family, teammates, and coaches on knowledge about the importance of nutrients also contributes negatively affects the performance of the athletes [12]. The adequate nutritional knowledge of TKD athletes is crucial for their ability to cope with the stressful situations they may experience physically, physiologically, and mentally during challenging training and competitions, and to perform high athletics performance [13]. The athletes should consider nutritional requirements, adequate calorie intake, adequate fluid intake and meal timing to achieve the desired success and performance [7, 13], thus well-balanced diet becomes the key to fulfill the daily nutrient requirements of an athlete's [14].

The previous evidence suggests that nutrition can affect health, body weight and composition, substrate availability during exercise, recovery after exercise, and eventually resulting enhance in sports performance [7]. Good nutrition assists in the ability to train intensely, and in muscle recovery and metabolic adaptations to athletes [2]. Adequate energy should derive from a wide variety of available foods that can be daily achieved through nutrition management, including the regulated intake of carbohydrates, fats, protein, vitamins, minerals, and water [15]. Optimal dietary carbohydrate needs to maintain blood glucose levels during exercise and replace muscle glycogen [7]. High-quality protein is needed to support muscle protein synthesis, reduce muscle protein breakdown and repairs muscle damage [16]. In addition, the optimal timing of protein intake should also be considered when determining and prescribing protein requirements, as this can lead to faster recovery times and improved adaptation after training [15]. An adequate amount of fat is necessary to consume to ensure optimal health, maintenance of energy balance, optimal intake of fatty acids, and fat-soluble vitamins and to replenish intramuscular triacylglycerol stores $[7,15]$. According to the joint position statement authored by the ADA and ACSM, Carbohydrate and protein recommendations for endurance and strength-trained athletes range from $6-10 \mathrm{~g} / \mathrm{kg}$ body weight, and $1.2-1.7 \mathrm{~g} / \mathrm{kg}$ body weight respectively as well as fat intake should range from $20-30 \%$ of total energy intake [7]. Fluid intake recommended at a rate of $0.5-2 \mathrm{l} /$ hour, which needs to maintain fluid balance and prevent dehydration. Also should be frequent (every 5-20 minutes) ingestion of small amounts of fluids (150-200 ml) [15]. Optimal micronutrients are essential for athletes in line with their metabolic demands. Increases in hemoglobin productions, blood volume, and muscle mass are normal characteristics of growth and maturation and account for the majority of amplified iron needs $[7,17]$. The ACSM recommended that no additional vitamin and mineral supplementation is needed if an athlete 
obtains sufficient energy from wide variety of foods [7]. Supplementation may be individually prescribed for certain athletes, who are restricting, energy intake, vegetarians, and recovering from injury or with special medical condition [7].

There is a paucity of evidence-based studies for the determining factors of nutritional knowledge, practice, different supplement use, and nutrient intake with athletic performance among TKD players in the Nepalese context. Thus, this study aimed to generate empirical evidence on nutritional knowledge, practice, the prevalence of supplements use, nutrient intake, and associated athletic performance among TKD players.

\section{Methods}

\section{Study design and setting}

An analytical cross-sectional study was conducted among TKD players of Kathmandu Metropolitan City, Nepal between August 2019 and January 2020. Kathmandu Metropolitan City is the capital city where about $20 \%$ of the country's urban population resides [18]. Likewise, the city is the center for the majority of sports schools, and 50 out of 85 Taekwondo schools of the country are located within this area [5]. The athletes who were actively involved in the Taekwondo game and aged 15-36 years were included in the study. Taekwondo players who were absent on that day of data collection and with a special medical condition like illness were excluded from the study.

\section{Sample size, sampling strategy}

The sample size of 293 was calculated using a single proportional formula $n=Z^{2} p q / d^{2}$ taking $50 \%$ proportion rate with a level of significance at $5 \%$. Where $Z$ = standard normal deviation and equals 1.96 at a level of significance; $p$ is the prevalence of the outcome of interest which was set at 0.5 considering the unknown prevalence of nutritional knowledge or nutritional practice among TKD players in the study area; $q=1$-p; and the margin error ( $d$ ) was set at $6 \%$ and $10 \%$ non-response rate was added.

A two-stage cluster random sampling technique was used to select the desired number of respondents for the study. In the first stage, we considered each of the 35 wards within Kathmandu Metropolitan City as an individual cluster, and then we randomly selected 12 clusters out of 35 clusters. In the second stage, we randomly selected two Taekwondo schools through the lottery method from the lists of the clubs from each cluster. Finally, we selected 24 Taekwondo schools for the study and interviewed all players who meet the study criteria. The list of schools was obtained from the Nepal Taekwondo Association (NTA) website [5].

\section{Data collection and study variables}

Data were collected by trained undergraduate public health students provided with three days of training that included the objective of the study, data collection procedure, sampling method, ethical aspects of the study, and data entry techniques. Face-to-face interviews were conducted using pre-tested semistructured questionnaires. Interviews were conducted at the Taekwondo School's premises or the training grounds at least 45 minutes before or after the training. The questionnaire consisted of three parts: (1) socio-demographic information (age, sex, education, religion, ethnicity, occupation, monthly income, family type, and smoking habit and alcohol consumption habit) and anthropometric characteristics (height, weight, and BMI), (2) nutritional knowledge, nutritional practice, nutrient intake, and supplement use and (3) exercise-related characteristics: training hour per day, handgrip strength as an athletic performance using a handgrip dynamometer. All the tools were originally developed into the English language. Further, the tools were translated into the Nepali language and back-translated into the English language to ensure the originality of the questionnaire remains unchanged. Pretesting of the tools was carried among 30 Taekwondo players from the clubs located in the areas of Lalitpur Metropolitan City.

\section{Outcome variable}

Handgrip strength (HGS), as an indirect measure of athlete performance, was assessed with the handgrip dynamometer. Measurements were performed for both hands, and handedness (dominance and non-dominance) was determined based on self-report and the dominant handgrip strength (DHGS) was taken for analysis $[19,20]$. HGS was measured using a standard adjustable digital handgrip dynamometer (Hand Grip Dynameters Labappara, Ambala Cantt, Haryana of India) at the standing position with shoulder adducted and neutrally rotated and elbow in full flexion. The dynamometer was held freely without support. The participants were asked to squeeze the handle maximally and to sustain this for $3-5$ seconds. All measurements were performed for both hands, and measurement was performed thrice, and the mean value was documented. One-minute rest was provided between each attempt, and hands were alternated to minimize fatigue effects. The results were documented in kilogram-force (kgf). The handgrip dynamometer was calibrated before each assessment.

\section{Predictor variables}

Information on participants' age, sex, ethnicity, religion, education, monthly income, sources of information, consumption of alcohol, and tobacco, nutrition knowledge, practice, nutrient intake, and supplements use were collected.

Questionnaires on nutritional knowledge and practice were adapted from previous works [20-22]. The mean nutrition knowledge score was calculated based on the responses of the participants. The responses of the question were scored one for every correct answer and zero for every wrong answer or not sure response. All the scores of the responses were added and the mean nutrition knowledge score was calculated. The participants who scored less than the mean score were classified as having poor knowledge while those scored equals to or more than the mean score were classified as having good NK [20]. The mean nutrition practice score was calculated based on the responses of the participants. The scoring process for NP and categorizing poor NP and good NP were similar to the procedure used for the classification of nutrition knowledge [20]. 
Pre-tested 24-hour dietary recall tool, based on Nepalese food and beverage was used to assess the previous 24 hours (midnight to midnight) nutrient intake of the participants. During 24-hour recall, the athletes were asked to name all the food and drink items consumed during the preceding day, including anything consumed outside the home and the time of consumption was also recorded. If multiple servings of the same food items were reported to be consumed in a single eating occasion then these amounts were combined to a single portion. The portion size of items consumed was estimated using graduated measuring cylinder and standard weight for foods that are served as a unit (boiled egg, bread slice), as per the principle and guideline of the Indian Institute for Medical Research (ICMR) [23]. Based on the information obtained from the $24 \mathrm{hr}$ dietary recall method, the amount of foods was then converted into daily nutrient intakes. The mean daily intake of total calorie, carbohydrate, protein, fats, calcium, and iron over $24 \mathrm{hr}$ recalls was calculated accordingly using the Nutrition Society of India (NSI) diet calculator developed by the National Institute of Nutrition, ICMR, Hyderabad, India [24].

The anthropometric measurements including weight and height of the participants were measured according to standardized procedures. Weight was measured to the nearest $0.1 \mathrm{~kg}$ using a digital weighing machine three times and the average values were documented. Height was measured in the standing position to the nearest $0.1 \mathrm{~cm}$ with a portable stadiometer three times with one-minute rest in between and the mean value was documented. The body mass index (BMI) was calculated using weight $(\mathrm{kg})$ divided by height squared $\left(\mathrm{m}^{2}\right)$ and categorized using the World Health Organization (WHO) cut-off points for BMI [25].

\section{Data management and analysis}

Data checking, compiling, and editing was done manually to ensure completeness and accuracy before data were entered for analysis. Pre and post coding was done. The collected data were entered into EpiData software 3.1v and transferred into STATA version 14.1 (StataCorp LP, College Station, Texas) for statistical analysis. The normality of the distribution of continuous variables was evaluated using the Kolmogorov-Smirnov test, and skewness-kurtosis test The descriptive results were presented in the form of mean, standard deviation, frequency, and percentage for normally distributed data and non-normally distributed data were expressed as median and interquartile range. Pearson's chi-square ( $\chi 2$ ) was applied for categorical variables, and independent sample ttest and one-way analysis of variance (ANOVA) tests were performed to observe differences in socio-demographic characteristics and athletic performance. Wilcoxon signed-rank test was used to assess the macro and micronutrient intake compared to the corresponding RDA of TKD players. Pearson correlation and simple linear regression analysis were used to observe the relationship between the predictor and outcome variables. The statistical significance was considered at p-value $<0.05$ and $95 \%$ confidence interval (Cl).

\section{Ethical considerations}

The ethical clearance for this study was obtained from the ethical review board of the Nepal Health Research Council (Ref.no 53/2019). Formal permission was also obtained from the respective Taekwondo schools. Written consent was obtained from all parents or legal guardians for eligible participants who were aged $\leq 18$ years, and participants themselves for aged $>18$ years before proceeding to data collection. The data collectors shared the objectives of the study among each athlete, and coaches of respective schools before the data collection. Participants were informed about voluntary participation, their right to refusal at any point, and the confidentiality of their identity.

\section{Results}

\section{Characteristics of the participants}

Out of 293 participants, $63.1 \%$ were male and $36.8 \%$ were female. More than half of the participants (55.4\%) had completed a higher secondary or higher level of education while $45 \%$ had completed secondary or lower level of education. About three-fourth of the participant (73\%) were engaged in less than 4 hours of training per day while the one-fourth of them were engaged in $\geq 4$ hours of training per day. The majority of the participants did not smoke (97.6\%) and consumed alcohol (97.6\%). The mean ( \pm SD) scores of NK and NP were $9.00( \pm 2.04)$ and $10.24( \pm 1.83)$ respectively. More than half of the participants $(56.3 \%$ and $55.6 \%$ ) had poor NK and NP score respectively. The mean ( \pm SD) age of the participants was $18.89( \pm 4.56)$ years $($ Table 1$)$. The majority of the participants (92\%) did not use any supplements. The most consumed nutritional supplements were protein powder (Fig. 1). Similarly, the majority of the athletes had poor nutritional knowledge score also had poor nutrition practice scores with statistically significant $\left(\chi^{2}=12.99, p<0.001\right)(T a b l e ~ 2)$. 
Table 2

Socio-demographic and anthropometric characteristics with DHGS score of the study participants $(n=293)$

\begin{tabular}{|c|c|c|c|c|}
\hline Variables & Characteristics & Frequency (\%) & Mean \pm SD & P-value 1,2 \\
\hline \multirow[t]{2}{*}{ Sex } & Male & $185(63.14)$ & $38.37 \pm 17.34$ & $<0.001^{*}$ \\
\hline & Female & $108(36.86)$ & $24.18 \pm 11.08$ & \\
\hline \multirow[t]{2}{*}{ Religion } & Hindu & $208(70.99)$ & $34.43 \pm 17.61$ & $0.020^{*}$ \\
\hline & Non Hindu & $85(29.01)$ & $30 \pm 14.15$ & \\
\hline \multirow[t]{2}{*}{ Ethnicity } & Advantage ethnic groups & $131(44.71)$ & $33.05 \pm 17.20$ & 0.532 \\
\hline & Disadvantage ethnic group & $162(55.29)$ & $33.21 \pm 30.65$ & \\
\hline \multirow[t]{2}{*}{ Education level } & Secondary or lower & $132(45.05)$ & $27.91 \pm 16.49$ & $<0.001^{*}$ \\
\hline & Higher secondary or above & $161(54.95)$ & $37.43 \pm 15.80$ & \\
\hline \multirow[t]{2}{*}{ Occupation } & Students & $221(75.43)$ & $29.57 \pm 14.89$ & $<0.001^{*}$ \\
\hline & Service & $72(24.57)$ & $44.11 \pm 17.57$ & \\
\hline \multirow[t]{2}{*}{ Monthly family income (NRs) (1USD = 110NRs) } & $<50,000$ & $205(69.97)$ & $32.49 \pm 16.44$ & 0.310 \\
\hline & $\geq 50,000$ & $88(30.03)$ & $34.66 \pm 17.54$ & \\
\hline \multirow[t]{2}{*}{ Training hour per day } & $<4$ hours & $214(73.04)$ & $29.64 \pm 14.63$ & $<0.001^{*}$ \\
\hline & $\geq 4$ hours & $79(26.96)$ & $42.63 \pm 18.56$ & \\
\hline \multirow[t]{2}{*}{ Smoking habit } & Yes & $7(2.39)$ & $42.42 \pm 18.27$ & 0.138 \\
\hline & No & $286(97.61)$ & $32.91 \pm 16.71$ & \\
\hline \multirow[t]{2}{*}{ Consumption of alcohol } & Yes & $7(2.39)$ & $48.21 \pm 15.44$ & $0.015^{*}$ \\
\hline & No & $286(97.61)$ & $32.77 \pm 16.66$ & \\
\hline \multirow[t]{2}{*}{ Family type } & Nuclear & $165(56.31)$ & $32.56 \pm 16.92$ & 0.501 \\
\hline & Joint & $128(43.69)$ & $33.89 \pm 16.62$ & \\
\hline \multirow[t]{3}{*}{ BMI $\left(\mathrm{kg} / \mathrm{m}^{\wedge} 2\right)$} & Underweight & $56(19.11)$ & $24.45 \pm 11.00$ & $<0.001^{*}$ \\
\hline & Normal & $231(78.84)$ & $35.00 \pm 17.22$ & \\
\hline & Overweight & $6(2.05)$ & $42.66 \pm 18.73$ & \\
\hline \multirow[t]{2}{*}{ Nutrition knowledge score } & Poor & $165(56.31)$ & $31.78 \pm 16.19$ & 0.116 \\
\hline & Good & $128(43.69)$ & $34.89 \pm 17.40$ & \\
\hline \multirow[t]{2}{*}{ Nutrition practice score } & Poor & $163(55.63)$ & $33.26 \pm 16.74$ & 0.889 \\
\hline & Good & $130(44.37)$ & $32.99 \pm 16.88$ & \\
\hline \multirow[t]{2}{*}{ Sports supplements use } & Yes & $21(7.17)$ & $30.92 \pm 16.63$ & 0.530 \\
\hline & No & $272(92.83)$ & & \\
\hline Age (years) & - & - & $18.89 \pm 4.56$ & - \\
\hline Height (feet) & - & - & $5.24 \pm 0.44$ & - \\
\hline Weight (kg) & - & - & $52.01 \pm 11.09$ & - \\
\hline $\operatorname{BMI}\left(\mathrm{kg} / \mathrm{m}^{\wedge} 2\right)$ & - & - & $20.37 \pm 2.5$ & - \\
\hline $\begin{array}{l}\text { Right handgrip } \\
\text { strength score }\end{array}$ & - & - & $35.47 \pm 16.97$ & - \\
\hline Left handgrip strength score & - & - & $30.82 \pm 17.69$ & - \\
\hline \multicolumn{5}{|c|}{ 1,2 denotes independent sample t-test and one-way ANOVA were used for DHGS; } \\
\hline DHGS: Dominant handgrip score & & & & \\
\hline
\end{tabular}


Table 2

Nutritional knowledge and nutrition practice among Taekwondo players $(n=293)$

\begin{tabular}{|c|c|c|c|c|c|}
\hline \multirow{2}{*}{$\begin{array}{l}\text { Variables } \\
\text { Nutritional knowledge score }\end{array}$} & & \multicolumn{4}{|c|}{ Nutritional practice score } \\
\hline & & Poor & Good & $x$ test & P-value \\
\hline & & $\mathrm{n}(\%)$ & $\mathrm{n}(\%)$ & & \\
\hline & Poor & $107(64.85)$ & $58(35.15)$ & 12.99 & $<0.001^{*}$ \\
\hline & Good & $56(43.75)$ & $72(56.25)$ & & \\
\hline & Total & $163(55.63)$ & $130(44.37)$ & & \\
\hline
\end{tabular}

Table 1. Socio-demographic and anthropometric characteristics with DHGS score of the participants $(n=293)$

\section{Nutrient intakes among players}

The results presented in Table 2, show participants were found to be consuming nutrients below their recommended daily dietary requirements. The median (IQR) energy intake was $2367.86(2035,2716.83) \mathrm{kcal} /$ day, which is equivalent to $77 \%$ of the RDA for athletes. The median (IQR) percentage of carbohydrate, protein, and fat intake of the participants was $71.41(66.04,76.79) \%, 13.28(11.36,15.60) \%$, and $15.85(11.55,18.94) \%$ respectively. The carbohydrate intake was equivalent to $100 \%$ of RDA's recommended value for athletes within this population. The result shows the demand for carbohydrates was met as per RDA value. The protein intake was equivalent to $58 \%$ of RDA's recommended value for athletes within this population. The fat intake was equivalent to $61 \%$ of RDA's recommended value for athletes within this population. The median (IQR) calcium and iron intake were $416(178,448) \mathrm{mg}$ and $7(3.8,12) \mathrm{mg}$ respectively. The calcium intake was equivalent to $47 \%$ of RDA's recommended value for athletes within this population. The iron intake was low and equivalent to $32 \%$ of RDA's recommended value for athletes within this population.

Table 3

Description of daily nutrient intake per day compared to corresponding RDA of Taekwondo players $(n=293)$

\begin{tabular}{|c|c|c|c|c|}
\hline Nutrient intake & Median $(25,75)$ & $\mathrm{RDA}^{1}$ & Percent meeting lower than RDA ${ }^{2}$ & P value $^{3}$ \\
\hline Total energy (kcal) & $2367.86(2035,2716.83)$ & 3600 & $77 \%$ & $<0.001^{*}$ \\
\hline Carbohydrate (\%) & $71.41(66.04,76.79)$ & 65 & $100 \%$ & $<0.001$ \\
\hline Protein (\%) & $13.28(11.36,15.60)$ & 15 & $58 \%$ & $<0.001^{*}$ \\
\hline Fat $(\%)$ & $15.85(11.55,18.94)$ & 20 & $61 \%$ & $<0.001^{*}$ \\
\hline Calcium (mg) & $416(178,448)$ & 800 & $47 \%$ & $<0.001^{*}$ \\
\hline Iron (mg) & $7(3.8,12)$ & 28 & $32 \%$ & $<0.001^{*}$ \\
\hline \multicolumn{5}{|c|}{ Median $(25,75)$ : median and interquartile range } \\
\hline \multicolumn{5}{|c|}{ RDA $^{1}$ :Recommended Dietary Allowance for Weight division category Group-IV of athletes [37] } \\
\hline \multicolumn{5}{|c|}{${ }^{2}$ Percent of individuals with intakes lower than the adequate intake (AI) level } \\
\hline \multicolumn{5}{|c|}{${ }^{3}$ wilcoxon sign-ranked test } \\
\hline \multicolumn{5}{|c|}{ *denotes statistically significant at $p<0.05$} \\
\hline
\end{tabular}

\section{Correlation of athletic performance with different covariates}

Table 4 depicts the correlation of anthropometric measurements, nutrition knowledge, practice, supplements use, and nutrient intake with athletic performance among Taekwondo players. Various factors were found to have a positive correlation with athletic performance. Nutritional knowledge score $(r=0.117, p<$ 0.05), height $(r=0.538, p<0.05)$, weight $(r=0.651, p<0.05)$, BMI $(r=0.347, p<0.05)$, fat $(r=0.075, p<0.05)$, and energy $(r=0.127, p<0.05)$ intake were significant positive correlation with handgrip strength of athletes. 
Table 4

Correlation of anthropometric measurements, nutrition knowledge, practice and nutrient intake with athletic performance among Taekwondo players $(n=293)$

\begin{tabular}{|c|c|c|c|c|c|c|c|c|c|c|c|c|c|}
\hline & Height & Weight & BMI & $\begin{array}{l}\text { DHG } \\
\text { score }\end{array}$ & $\begin{array}{l}\text { NK } \\
\text { score }\end{array}$ & $\begin{array}{l}\text { NP } \\
\text { score }\end{array}$ & $\begin{array}{l}\text { Supplements } \\
\text { use }\end{array}$ & $\begin{array}{l}\text { CHO } \\
\text { Intake }\end{array}$ & $\begin{array}{l}\text { Protein } \\
\text { Intake }\end{array}$ & $\begin{array}{l}\text { Fat } \\
\text { Intake }\end{array}$ & $\begin{array}{l}\text { Calcium } \\
\text { Intake }\end{array}$ & $\begin{array}{l}\text { Iron } \\
\text { Intake }\end{array}$ & $\begin{array}{l}\text { Energy } \\
\text { Intake }\end{array}$ \\
\hline Height (feet) & 1 & & & & & & & & & & & & \\
\hline Weight (kg) & $0.719^{*}$ & 1 & & & & & & & & & & & \\
\hline BMI $\left(k g / m^{2}\right)$ & $0.131^{*}$ & $0.656^{*}$ & 1 & & & & & & & & & & \\
\hline DHG score & $0.538^{*}$ & $0.651^{*}$ & $0.347^{*}$ & 1 & & & & & & & & & \\
\hline NK score & 0.245 & 0.104 & $0.148^{\star}$ & $0.117^{*}$ & 1 & & & & & & & & \\
\hline NP score & 0.039 & 0.0395 & 0.062 & 0.008 & $0.0210^{*}$ & 1 & & & & & & & \\
\hline $\begin{array}{l}\text { Supplements } \\
\text { use }\end{array}$ & -0.035 & -0.014 & -0.018 & 0.0501 & -0.022 & -0.098 & 1 & & & & & & \\
\hline $\begin{array}{l}\text { CHO Intake } \\
\text { (g) }\end{array}$ & $0.213^{*}$ & 0.071 & $-0.151^{*}$ & 0.085 & -0.016 & -0.096 & -0.064 & 1 & & & & & \\
\hline $\begin{array}{l}\text { Protein } \\
\text { Intake(g) }\end{array}$ & $0.156^{*}$ & $0.169^{*}$ & 0.065 & $0.128^{*}$ & $0.043^{*}$ & 0.106 & -0.034 & $0.124^{*}$ & 1 & & & & \\
\hline $\begin{array}{l}\text { Fat Intake } \\
\text { (g) }\end{array}$ & 0.068 & $0.072^{*}$ & 0.001 & $0.075^{*}$ & 0.029 & -0.007 & 0.086 & -0.96 & $0.362^{*}$ & 1 & & & \\
\hline $\begin{array}{l}\text { Calcium } \\
\text { Intake (mg) }\end{array}$ & 0.072 & 0.053 & 0.063 & 0.054 & 0.114 & 0.0818 & -0.063 & $0.152^{*}$ & -0.109 & 0.019 & 1 & & \\
\hline $\begin{array}{l}\text { Iron Intake } \\
(\mathrm{mg})\end{array}$ & -0.001 & 0.035 & -0.019 & -0.004 & 0.031 & 0.006 & 0.076 & $-0.079^{\star}$ & -0.017 & 0.067 & $-0.114^{*}$ & 1 & \\
\hline Energy (kcal) & $0.259^{*}$ & $0.118^{\star}$ & $-0.129^{*}$ & $0.127^{*}$ & -0.019 & -0.082 & -0.063 & $0.944^{\star}$ & $0.376^{*}$ & $0.127^{*}$ & $.162^{*}$ & -0.072 & 1 \\
\hline
\end{tabular}

*denotes statistically significant at $\mathrm{p}<0.05$

DHG: Dominant handgrip score, NK: Nutrition knowledge, NP: Nutrition practice

Table 5

linear regression analysis of anthropometric measurement, nutrition knowledge, practice, and nutrient intake with athletic performance among

\begin{tabular}{|c|c|c|c|}
\hline Variables & $\beta(95 \% \mathrm{Cl})$ & SE & P-value \\
\hline Training hour per day & $0.41(-0.09-0.91)$ & 0.61 & $<0.001^{*}$ \\
\hline $\mathrm{BMI}\left(\mathrm{kg} / \mathrm{m}^{\wedge} 2\right)$ & $0.35(0.09-0.61)$ & 0.37 & $<0.001^{*}$ \\
\hline Nutrition knowledge score & $0.13(0.01-0.25)$ & 0.47 & $0.024^{*}$ \\
\hline Nutrition practice score & $-0.03(0.001-0.061)$ & 0.53 & 0.543 \\
\hline \multicolumn{4}{|l|}{ Nutrient intake } \\
\hline Energy (kcal) & $0.13(0.12-0.14)$ & 0.001 & $0.035^{*}$ \\
\hline Carbohydrate (gm) & $0.05(0.04-0.052)$ & 0.002 & 0.343 \\
\hline Protein (gm) & $0.13(0.12-0.14)$ & 0.01 & 0.124 \\
\hline Fat (gm) & $0.11(0.10-0.12)$ & 0.007 & 0.054 \\
\hline Calcium (mg) & $0.05(0.04-0.06)$ & 0.004 & 0.425 \\
\hline Iron (mg) & $0.02(0.01-0.03)$ & 0.13 & 0.667 \\
\hline \multicolumn{4}{|c|}{ Adjusted R-squared $=0.237, F(10,282)=10.09, P<0.001$} \\
\hline
\end{tabular}

Table 5 depicts the linear regression analysis of anthropometric measurements, nutrition knowledge, practice, and nutrient intake with athletic performance among Taekwondo players. The DHGS was positively associated with training hour per day $(\beta=0.41,95 \% \mathrm{Cl}:-0.09-0.91, \mathrm{P}<0.001), \mathrm{BMI}(\beta=0.35,95 \% \mathrm{Cl}$ : $0.09-0.61, P<0.001)$, NK score $(\beta=0.13,95 \% \mathrm{Cl}: 0.01-0.25, p=0.024)$, and energy intake $(\beta=0.13,95 \% \mathrm{Cl}: 0.12-0.14, p<0.035)$. About $23.7 \%$ of the variance in the DHGS, which is our measure of athletic performance can be explained by this model. 


\section{Discussion}

This is the first study of its kind to assess the association of nutrition knowledge, practice, and nutrient intake and supplementation use with athletic performance among Taekwondo players in Nepal. Good nutritional knowledge, practice, and adequate nutrient intake are considered a crucial component that contributes to a basic part in enhancing athletic performance among athletes [26].

In this study, based on the correct response of the nutrition knowledge and practice score, the study participants exhibited a relatively low level of nutrition knowledge and practice compared to previous findings, a study conducted by Folasire OF et al (2015) and Abbey et al (2017), where less than half (42.8\%) and $(35 \%)$ had poor nutritional knowledge $[20,27]$. However, our result is in line with the other studies report where overall nutrition knowledge scores were low $[9,28]$. Optimum nutrition knowledge is an essential factor for promoting athletic success to the sportsperson [8, 9]. Inadequate nutrition knowledge can have a serious impact on the nutritional status and performance of athletes [10]. The study conducted by Walsh et al (2011) showed that nutrition knowledge and attitudes affect eating habits and inadequate nutritional knowledge may contribute to poor dietary behaviors [11].

This study revealed that those athletes who had poor nutrition knowledge were found to have poor nutrition practice scores. These findings were found similar to previous results where the correlation between nutrition knowledge and practice score of athletes were found statistically significant [20, 29]. The prevalence of supplement use in the current study was found to be lower than that reported in other studies [8, 13]. Overall, 7.17\% of Taekwondo players in our study used some form of supplements. Likewise, Muwonge $\mathrm{H}$ et al (2017) also reported the prevalence of supplements used was 13.4\% [30], which is also low compared to previous study findings $[8,13,31]$. The professional TKD players may readily use nutritional supplements mainly to maintain their health and improve athletic performance. The possible explanation for these findings could be that the assessment tools for supplements use adopted by the current study may have underestimated the true prevalence of supplements use in these populations.

In this study, a total energy intake, protein, fat, calcium, and iron were significantly lower than the corresponding RDA except for carbohydrates intake. Every athlete including TKD players needs adequate calorie from the diet in terms of optimum quality and quantity before, during, and after exercise for improved athletic performance [2]. Likewise, adequate nutrient intake and good nutrition knowledge have been recognized as key factors that play an important role in improving the athletic performance in terms of improved quality of training and speedy recovery from injury in athletes. The median carbohydrate intake of the participants was $71.4 \%$ in this study. This is only equivalent to $100 \%$ of RDA's recommended value for athletes within this population. This result is consistent with results from Wierniuk et al (2013) and Ali A et al (2015) findings [10, 32]. Carbohydrate is essential not only as a source of energy but also protects the protein from being exploited as an energy source $[33,34]$. Inadequate intake of carbohydrates increases the risk of injury and exaggerates deterioration of athletic performance [28,34]. Thus, carbohydrate intake before, during, and after exercise should be scaled up according to the characteristics of the event. Even small amounts of carbohydrate solution like mouth-rinsing without swallowing, increase athletic performance through the central nervous system [33].

The median protein intake of the participants was $13.28 \%$. The protein intake was found to be inadequate in this study, only meet $58 \%$ of corresponding RDA for athletes within this population. Inadequate protein consumption can have serious health problems in athletes such as inability to maintain proper body function and declining sports performance [7]. A previous study depicted that a protein intake of 1.4-2.0 g/kg body weight can improve body adaptability to intensive physical activity [35]. Adequate protein intake is a key role in the overall exercise training program, required for a proper and speedy recovery from injury, bolster immune function, and the growth and maintenance of lean body mass [35].

The median fat intake was found to be low (15.85\%) in this study, which is only equivalent to $61 \%$ of RDA recommended value for athletes within this population. This finding is inconsistent with other findings, where the fat intake was found to have higher than RDA [28, 32]. Fat is an essential component of a balanced diet, providing energy, optimum elements of cell membranes, and facilitation of the absorption of fat-soluble vitamins [36].

The median energy intake in these participants was $2367.86 \mathrm{kcal} /$ day, which is lower than the corresponding RDA, which is slightly lower than reported in the previous study in Indian Taekwondo athletes, with mean energy intakes $3129 \pm 518.95$ [4]. According to the Nutrition and Hydration Guidelines set under the collaboration of Indian Life Science Institute, National Institute of Nutrition and Sports Authority of India, weight division game such as TKD is categorized under Group-IV sport event which demands a minimum $3600 \mathrm{Kcal}$ of daily calorie, $65 \%, 15 \%$, and $20 \%$ should be yield from carbohydrate, protein, and fat respectively [37].

The median intake of micronutrients: calcium $(416 \mathrm{mg})$ and iron $(7 \mathrm{mg})$ were below the RDA, which can meet only $47 \%$ and $32 \%$ of RDA value for athletes within this population. These findings are in line with the results from the other studies [4,28], where their results also below the RDA. Adequate intake of iron, which is necessary to carry oxygen and maintaining energy production, is important for especially female athletes during the high-intensity exercise [38]. Likewise, a sufficient amount of calcium-rich diet contributes to bolster bone mineral density and prevent injury risk [28].

Anthropometric characteristics like height, weight, and BMI were significant positive correlation with athletic performance. These results are consistent with previous studies where they reported that handgrip strength had a strong correlation with various anthropometric characteristics [19, 20]. In this study, results indicated a significant relationship between NK score and athletic performance. Various previous studies were reported that nutrition knowledge was positively correlated with athletic performance $[11,20,29]$. Higher nutrition knowledge to the athletes, better the player's attitude and practice towards a sport-enhancing diet, resulting in athletes can perform a better athletic performance [29]. Likewise, total energy and fat intake were significantly positively correlated with handgrip strength of athletes. The previous study also reported that energy intake was positively associated with handgrip strength [20]. The most important component to optimize athletic performance through diet is to ensure the athlete is consuming enough calories to maintain positive energy balance [6, 15]. However, it might be challenging to meet the energy needs of athletes with a high volume of intense training. Insufficient energy intake can result in weight loss, especially lean muscle mass, injury, illness, increased prevalence of overtraining syndrome, and ultimately decreased exercise performance [39]. Moreover, in linear regression analysis, the DHGS were positively associated with training hours per day, BMI, NK score, and energy intake. These results are consistent with the findings from the study conducted by Folasire OF et al (2015). For better athletic performance by athletes, an adequate energy balance is 
needed, where energy balance occurs only when energy intake such as foods, fluids, and supplement products are equals energy expenditure [7]. Energy expenditure for various exercise is dependent on the duration, frequency, intensity of the exercise, sex, age, body size of the athletes. The more energy used in the exercise, the greater calories required to achieve energy balance [36].

Our study had a few limitations. The sample size used in this study was confined to Taekwondo players, thus we cannot generalize the findings to all types of sports., There are slight differences in nutritional requirements depending on the type of sports. We used a 24-hour dietary recall method which can underestimate true nutrient intake. Also, single 24-hr recall cannot identify within and between-person variations. Although other minerals and vitamins play a key role in human health and nutritional status, we included only calcium and iron as micronutrient intake. Since the information was collected through faceto-face using semi-structured questionnaires, response preference to some nutrition issues may lead to social desirability bias. Despite the mentioned limitations, our study has some strengths. Our study included an analysis of the correlation between nutritional knowledge, practice, and nutrient intake with athletic performance. This data provide insight into the potential factors influencing athletics performance which helps in forming the basis of targeted nutrition education programs. Since the majority of the national Taekwondo clubs located in Kathmandu Metropolitan City, the study sample is highly representative as it included all levels of players including the national level Taekwondo players of Nepal. The results of this study can be utilized in planning the health and development of Taekwondo players in Nepal and pave the way for the nutritional policy of other athletes as well. This study has also set the background to conduct further study to explore the determining factors for the nutritional knowledge and practices among Nepalese athletes.

\section{Conclusions}

To the best of our knowledge, this is the first study to present the findings on sports nutrition in a Nepalese context. The current study results indicated that there is a gap between knowledge of nutrition and nutritional practice among Taekwondo players. Total energy intake, protein, fat, calcium, and iron intake were exhibited low with respect to the current recommendations for athletes. BMI, nutritional knowledge, energy, and fat intake were positively associated with athletic performance. Inadequate consumption of the right diet before, during, and after competition due to lack of nutrition knowledge and dietary intakes may interfere with athletic performance. This paper suggests that sports nutrition research has contributed great implication of nutrition for athletes. Thus, further well-constructed longitudinal research in this area is warranted to identify the robust relationship between nutritional knowledge, practice, nutrient intake, and dietary supplements used for athletic performance among athletes of different sports. Providing nutrition education by dietitian/nutritionists can bridge the nutrition knowledge gap to equip sports nutrition and contribute to an enhanced understanding of dietary patterns and nutrient intakes among athletes. Also, regular measurements of the players' strength and their dietary intakes are crucial in maintaining the good health and optimizing the overall performance of the players.

\section{Abbreviations}

ADA

American Dietetic Association; ACSM:American College of Sports Medicine; BMI:Body mass index; Cl:Confidence interval; DHGS:Dominant handgrip strength; ICMR:Indian Institute for Medical Research; HGS:Handgrip strength; NK:Nutritional knowledge; NP:Nutrition practice; NTA:Nepal Taekwondo Association RDA:Recommended dietary allowances; TKD:Taekwondo; WHO:World Health Organization WTF:World Taekwondo Federation

\section{Declarations}

Ethical approval and consent to participants

The ethical clearance was obtained from the ethical review board of the Nepal Health Research Council (Ref.no 53/2019). Formal permission was also obtained from the respective Taekwondo schools. Informed verbal consent was obtained from all parents or legal guardians for eligible participants who were aged $\leq 18$ years, and respondents themselves for aged $>18$ years before proceeding to data collection. The data collectors shared the objectives of the study among each athlete, coaches of respective clubs before the data collection. Participants were informed about voluntary participation, their right to refusal at any point, and the confidentiality of their identity.

\section{Consent for publication}

Not applicable

\section{Availability of supporting data}

Dataset used in this study is available upon reasonable request to the corresponding author.

\section{Competing interest}

The authors have declared that no competing interest exists.

\section{Funding}


This research received no specific financial support from any funding agencies.

\section{Author's contributions}

DRSu. Roles: Research design, conceptualization idea, methodology, formal data analysis, interpretation, software, validation, writing an original draft, writing review, editing and overall supervision of the research. DRSi. Roles: Research design, conceptualization idea, methodology, Data analysis, interpretation, writing an original draft, writing review, editing and overall supervision of the research. MPB. Roles: Research design, data collection, data curation, writing an original draft, writing review, editing. VS. Roles: Writing an original draft, reviewing and editing, overall supervision of the research. KK. Roles: Writing an original draft, reviewing and editing, overall supervision of the research. PMSP: Writing an original draft, reviewing and editing, overall supervision of the research. All authors read and approved the final manuscript.

\section{Acknowledgments}

We would like to thanks all the participants who provided their valuable time, response, and participation in the study. Our gratitude to all coaches and members of the Taekwondo schools for facilitation, and cooperation in undertaking this research.

\section{Author's information}

${ }^{1}$ Department of Nutrition and Dietetics, Nepal APF Hospital, Kathmandu, Nepal ${ }^{2}$ Department of Public Health, Asian College for Advance Studies, Purbanchal University, Lalitpur, Nepal

${ }^{3}$ Southeast Asia Development Actions Network, Lalitpur, Nepal

${ }^{4}$ Central Department of Public Health, Maharajgunj Medical Campus, Institute of Medicine, Tribhuvan University, Kathmandu, Nepal

${ }^{5}$ Group for Technical Assistance, Lalitpur, Nepal

${ }^{6}$ Department of Community Medicine, Maharajgunj Medical Campus, Institute of Medicine, Tribhuvan University, Kathmandu, Nepal

\section{References}

1. World Taekwondo Federation (WTF). World Taekwondo. 2020. http://www.worldtaekwondo.org/about-wt/taekwondo/.

2. Caramoci A, Paunescu C, Haddad M, Ionescu AM. Performance Optimization in Taekwondo: From Laboratory to Field. In: Performance Optimization in Taekwondo: From Laboratory to Field. 2014.

3. Kazemi M, Pieter W. Injuries at a Canadian National Taekwondo Championships: A prospective study. BMC Musculoskelet Disord. 2004;5:1-8. doi:10.1186/1471-2474-5-22.

4. Sarkar S, Debnath M, Chatterjee S, Karmakar N, Dey SK. Assessment of Nutritional Status, Body Composition Parameters, \& Physiological Profi les of Young Male Taekwondo and Wushu Players. Int J Sport Sci Med. 2018;2:1-7.

5. Nepal Taekwondo Association. Nepal Taekwondo Association, International Sports Complex Satdobato, Lalitpur, Nepal. 2020. http://www.taekwondonepal.org.np/.

6. 10.1007/978-1-59259-226-5_14

Leutholtz B, Kreider RB. Optimizing Nutrition for Exercise and Sport. In: Nutritional Health. Humana Press; 2001. p. 207-35. doi:10.1007/978-1-59259-2265_14.

7. Rodriguez NR, DiMarco NM, Langley S. Position of the American Dietetic Association, Dietitians of Canada, and the American College of Sports Medicine: Nutrition and athletic performance. J Am Diet Assoc. 2009;109:509-27.

8. Tawfik S, El Koofy N, Moawad EMI. Patterns of nutrition and dietary supplements use in young Egyptian athletes: A community-based cross-sectional survey. PLoS One. 2016;11:1-12.

9. Nazni P, Vimala S. Nutrition knowledge, attitude and practice of college sportsmen. Asian J Sports Med. 2010;1:93-100.

10. Ali A, Al-Siyabi MS, Waly MI, Kilani HA. Assessment of nutritional knowledge, dietary habits and nutrient intake of university student athletes. Pakistan $\mathrm{J}$ Nutr. 2015;14:293-9.

11. Walsh M, Cartwright L, Corish C, Sugrue S, Wood-Martin R. The body composition, nutritional knowledge, attitudes, behaviors, and future education needs of senior schoolboy rugby players in Ireland. Int J Sport Nutr Exerc Metab. 2011;21:365-76. doi:10.1123/ijsnem.21.5.365.

12. Shifflett B, Timm C, Kahanov L. Understanding of athletes' nutritional needs among athletes, coaches, and athletic trainers. Res Q Exerc Sport. 2002;73:357-62.

13. Seyhan S. Evaluation of the Use of Nutrition Support Products in Taekwondo Athletes. J Educ Learn. 2018;7:222.

14. Jamaluddin R, Redzwan SM, Cheong Hong C. Athlete's Nutrition Knowledge and Their Perception and Satisfaction in the Foodservice Quality of the Athlete's Cafeteria. J Foodserv Bus Res. 2014;17:242-56. 
15. Potgieter S. Sport nutrition: A review of the latest guidelines for exercise and sport nutrition from the American College of Sport Nutrition, the International Olympic Committee and the International Society for Sports Nutrition. South African J Clin Nutr. 2013;26:6-16.

16. Phillips SM, van Loon LJC. Dietary protein for athletes: From requirements to optimum adaptation. J Sports Sci. $2011 ; 29$ SUPPL. 1.

17. Ekblom B, Goldbarg AN, Gullbring B. Response to exercise after blood loss and reinfusion. J Appl Physiol. 1972;33:175-80. doi:10.1152/jappl.1972.33.2.175.

18. Government of Nepal, National Planning Comission, Central Bureau of Statistics(CBS). National Population and Housing Census 2011. 2012. http://old.cbs.gov.np/image/data/Population/National Report/National Report.pdf.

19. Koley S, Kaur SP. Correlations of handgrip strength with selected hand-arm-anthropometric variables in Indian inter-university female volleyball players. Asian J Sports Med. 2011;2:220-6. doi:10.5812/asjsm.34738.

20. Folasire OF, Akomolafe AA, Sanusi RA. Does Nutrition Knowledge and Practice of Athletes Translate to Enhanced Athletic Performance ? Cross-Sectional Study Amongst Nigerian Undergraduate Athletes. Glob J Health Sci. 2015;7:215-25.

21. Zawila LG, Steib C-SM, Hoogenboom B. The female collegiate cross-country runner: nutritional knowledge and attitudes. J Athl Train. $2003 ; 38: 67$.

22. Supriya V, Ramaswami L. Knowledge, attitude and dietary practices of track and field athletic men and women aged 18-22 years. Int $\mathrm{J}$ Innov Res Dev. 2013;2:399-404.

23. Kamala K, Bhaskaram P, Bhat RVRT. DIETARY GUIDELINES - A Manual. Natl Inst Nutr. 2011;3:139. http://ninindia.org/DietaryGuidelinesforNINwebsite.pdf.

24. National Institute of Nutrition (ICMR). Hyderabad, India. NSI Diet Calculator. http://www.nutritionsocietyindia.org/downloads.html. Accessed 4 May 2020.

25. World Health Organization (WHO). WHO Physical status: The use of and interpretation of anthropometry. Report of a WHO Expert Consultation. Geneva: World Health Organization. 1995. https://apps.who.int/iris/bitstream/handle/10665/37003/WHO_TRS_854.pdf?sequence=1.

26. Smith JW, Holmes ME, McAllister MJ. Nutritional Considerations for Performance in Young Athletes. J Sports Med. 2015;2015:1-13. doi:10.1155/2015/734649.

27. Abbey EL, Wright CJ, Kirkpatrick CM. Nutrition practices and knowledge among NCAA Division III football players. J Int Soc Sports Nutr. 2017;14:1-9.

28. Condo D, Lohman R, Kelly M, Carr A. Nutritional intake, sports nutrition knowledge and energy availability in female Australian rules football players. Nutrients. 2019;11:1-13.

29. Hornstrom GR, Friesen CA, Ellery JE, Pike K. Nutrition Knowledge, Practices, Attitudes, and Information Sources of Mid-American Conference College Softball Players. Food Nutr Sci. 2011;02:109-17.

30. Muwonge H, Zavuga R, Kabenge PA, Makubuya T. Nutritional supplement practices of professional Ugandan athletes: A cross-sectional study. J Int Soc Sports Nutr. 2017;14:1-10.

31. Braun H, Koehler K, Geyer H, Kleinert J, Mester J, Schänzer W. Dietary Supplement Use Among Elite Young German Athletes. 2009.

32. Wierniuk A, Włodarek D. Estimation of energy and nutritional intake of young men practicing aerobic sports. Rocz Państwowego Zakładu Hig. 2013;64:143-8.

33. Burke LM, Hawley JA, Wong SHS, Jeukendrup AE. Carbohydrates for training and competition. J Sports Sci. $2011 ; 29$ SUPPL. 1.

34. Cook CM, Haub MD. Low-carbohydrate Diets and Performance. Curr Sports Med Rep. 2007;6:225-9.

35. Campbell B, Kreider RB, Ziegenfuss T, La Bounty P, Roberts M, Burke D, et al. International Society of Sports Nutrition position stand: Protein and exercise. J Int Soc Sports Nutr. 2007;4:8. doi:10.1186/1550-2783-4-8.

36. Thomas DT, Burke LM, Erdman KA. Nutrition and Athletic Performance. Med Sci Sports Exerc. 2016;48:543-68.

37. National Institute of Nutrition, Sports Authority of India. Nutrition and Hydration Guidelines for Excellence in Sports Performance Sciences IL, Institute-India, National Institute of Nutrition, Sports Authority of India. Nutrition and Hydration Guidelines for Excellence in Sports Performance. 2007. http://www.ilsi-india.org/PDF/Conf. recommendations/Nutrition/Nutrition \& Hyd. Guidelines for Athletes Final report.pdf.

38. Hinton PS. Iron and the endurance athlete. Appl Physiol Nutr Metab. 2014;39:1012-8.

39. Kreider RB, Wilborn CD, Taylor L, Campbell B, Almada AL, Collins R, et al. ISSN exercise and sport nutrition review: Research and recommendations. J Int Soc Sports Nutr. 2010;7:1-43.

\section{Figures}




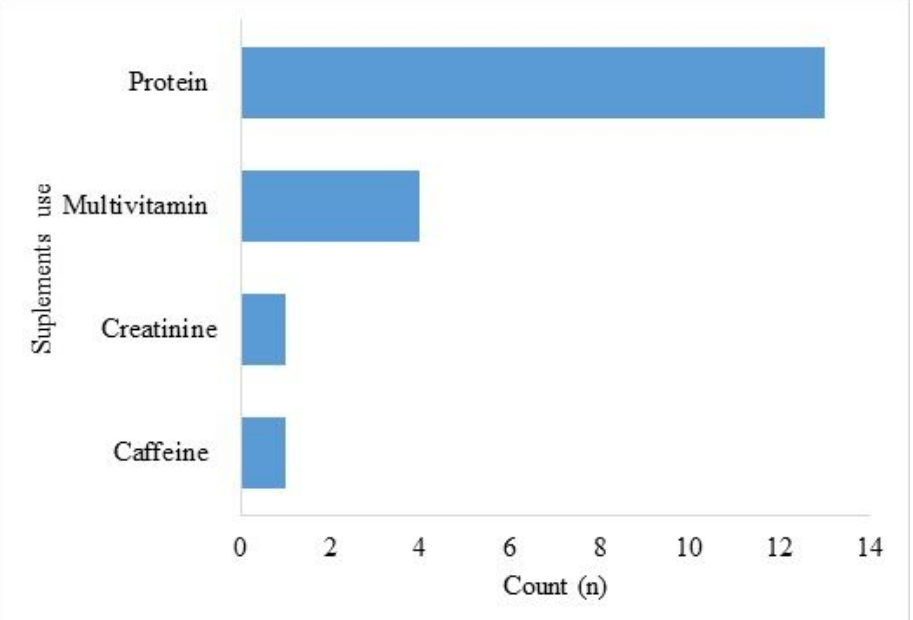

\section{Figure 1}

Type of supplements used by Taekwondo players $(n=21)$ 